\title{
Preoperative labs: Less is more
}

\author{
Carl L. Backer, MD, and Courtney A. Hardy, $\mathrm{MD}^{\mathrm{b}}$ \\ From the ${ }^{\mathrm{a} D i v i s i o n}$ of Cardiovascular-Thoracic Surgery, Department of Surgery and ${ }^{\mathrm{b}}$ Division of Anesthesiology, \\ Department of Anesthesiology, Ann \& Robert H. Lurie Children's Hospital of Chicago, Northwestern Univer- \\ sity Feinberg School of Medicine, Chicago, Ill. \\ Disclosures: Authors have nothing to disclose with regard to commercial support. \\ Received for publication Oct 20, 2016; accepted for publication Oct 21, 2016; available ahead of print Dec 6, \\ 2016. \\ Address for reprints: Carl L. Backer, MD, Division of Cardiovascular-Thoracic Surgery, Ann \& Robert H. Lurie \\ Children's Hospital of Chicago, 225 E Chicago Ave, mc 22, Chicago, IL 60611 (E-mail: cbacker@ \\ luriechildrens.org). \\ J Thorac Cardiovasc Surg 2017; 153:677 \\ $0022-5223 / \$ 36.00$ \\ Copyright (C) 2016 by The American Association for Thoracic Surgery \\ http://dx.doi.org/10.1016/j.jtcvs.2016.10.052
}

It appears that the dictum "less is more" applies to more than just architecture. This famous quote is from the late Mies van der Rohe, one of the most famous architects (especially in Chicago) of the 20th century. In their study published in this issue of the Journal, Nieto and colleagues from Texas Children's Hospital demonstrate that less is (also) more for routine preoperative laboratory testing in elective pediatric cardiothoracic surgical cases. ${ }^{1}$ The authors reviewed more than 1000 scheduled elective cases between 2012 and 2014. Routine laboratory testing resulted in only 6 cancellations, none of which was later found to be medically necessary. The average charge for these routine laboratory tests was slightly more than $\$ 2000$ per patient.

We congratulate the authors on examining what historically has been surgical/anesthesia dogma that all patients undergoing congenital cardiac surgery require multiple preoperative tests. This appears to be something that has been handed down from intern-to-intern and has never been critically examined for its actual necessity. The authors have put this practice in the spotlight, and now it is time for a change.

We always cringe when seeing a patient in the preoperative holding area who has been scheduled for another blood draw. Usual reasons for this include high potassium (in hemolyzed specimens) or a clotted coagulation profile. Our standard response is to cancel the blood draw and have the sample repeated once the child is asleep. In the great majority of cases, once the child is asleep in the operating room, an arterial line is placed, which provides easy access for blood draws. The stress on a family already worried about their child undergoing open-heart surgery does not need to be compounded by hearing the child screaming from another blood draw just before entering the operating room. In some cases, this can actually be dangerous for children with complex shunt-dependent cyanotic lesions.

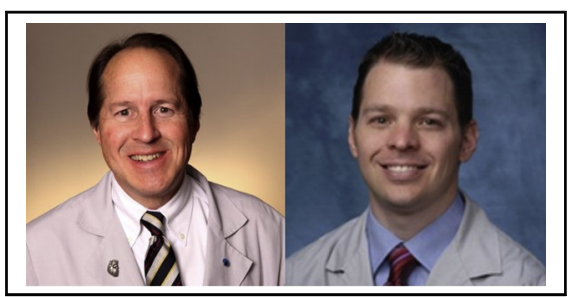

Carl L. Backer, MD, and Courtney A. Hardy, MD

Central Message

Routine preoperative laboratory testing is unnecessary for the majority of children undergoing elective pediatric cardiothoracic surgery.

See Article page 678.

Causing extra stress in these infants can result in elevated pulmonary vascular resistance and, in rare cases, cardiac arrest. It is time to eliminate "routine" preoperative laboratory testing.

This analysis by the Texas Children's group is very well done and captures a substantial number of patients. Based on more than 30 years of experience in congenital heart surgery and a review of this carefully written article, we do not believe that a prospective trial is needed to analyze this. We completely agree with the authors that routine laboratory testing does not appear to significantly impact decision making in elective pediatric cardiac surgery. The decision to order specific screening tests should be clinically driven by a thorough history and physical examination of the patient. Certainly some patients will require preoperative laboratory testing (eg, patients on coumadin therapy); however, a rational, goal-directed, precision medicine approach should provide safe preparation for surgery without a dogmatic approach to preoperative laboratory testing. In addition, as the move from volume to valuebased care evolves, more payers will be looking at ways to reduce costs in a bundled payment system. The savings to payers of more than $\$ 2000$ per patient and the concomitant decreased stress for families will be immense. Less will be more.

\section{Reference}

1. Nieto RM, De León LE, Diaz DT, Krauklis KA, Fraser CD Jr. Routine preoperative laboratory testing in elective pediatric cardiothoracic surgery is largely unnecessary. J Thorac Cardiovasc Surg. 2017;153:678-85. 